\title{
Writing and mathematical problem solving in Grade 3
}

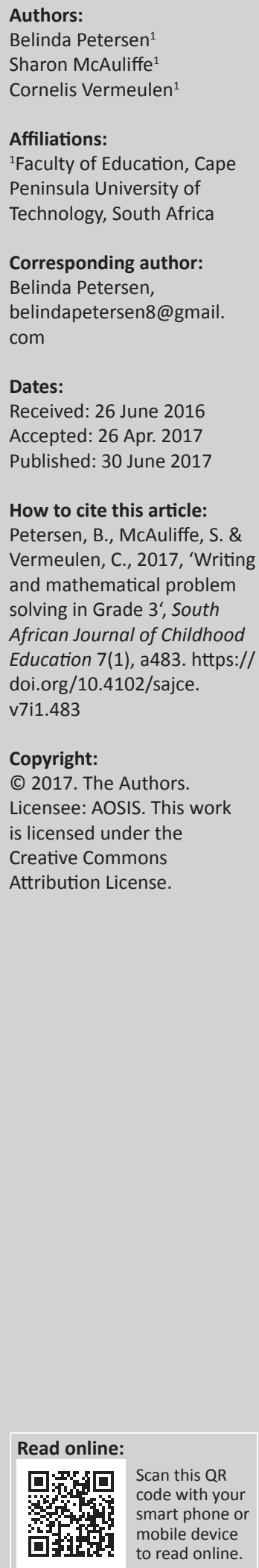

This article looks at writing tasks as a methodology to support learners' mathematical problemsolving strategies in the South African Foundation Phase context. It is a qualitative case study and explores the relation between the use of writing in mathematics and development of learners' problem-solving strategies and conceptual understanding. The research was conducted in a suburban Foundation Phase school in Cape Town with a class of Grade 3 learners involved in a writing and mathematics intervention. Writing tasks were modelled to learners and implemented by them while they were engaged in mathematical problem solving. Data were gathered from a sample of eight learners of different abilities and included written work, interviews, field notes and audio recordings of ability group discussions. The results revealed an improvement in the strategies and explanations learners used when solving mathematical problems compared to before the writing tasks were implemented. Learners were able to reflect critically on their thinking through their written strategies and explanations. The writing tasks appeared to support learners in providing opportunities to construct and apply mathematical knowledge and skills in their development of problem-solving strategies.

\section{Introduction}

\section{Significance of the study}

The mathematics curriculum currently used in South African classrooms emphasises problem solving to develop critical thinking (South Africa Department of Basic Education [DBE] 2011a:5). However, based on the performance of South African learners in comparative international studies in mathematics, such as Trends in International Mathematics and Science Study and Southern Africa Consortium for Monitoring Educational Quality, there is concern regarding their competence when solving mathematical problems and their use of meaningful strategies (Ndlovu \& Mji 2012). Despite the use of standardised tests such as the Annual National Assessments (ANAs) and the provincial systemic tests conducted in the Western Cape, results reflect a difference between the ability to use procedural and conceptual knowledge. Learners often do not achieve the minimum requirements of their grade levels, especially in the area of problem solving. Learners' lack of achievement in basic numeracy skills in the ANA, especially in Grades 3 and 4, is highlighted by Graven et al. (2015:69).

As a Foundation Phase teacher, the researcher has been observing learners for many years while solving mathematical problems. During these observations, learners reflected their lack of competence in writing coherent solutions and explaining their solutions to the teacher and/or peers. Some learners appeared to wait for instructions from the teacher giving specific methods and procedures to solve the problem. It seemed that learners generally had difficulty applying mathematical concepts they had previously learned in their problem-solving strategies.

\section{Literature review}

Writing is essential in supporting the development of mathematical knowledge and its application to problem-solving strategies. It helps learners clarify, define and express their thinking as well as examine their ideas and reflect on what they have learned in order to deepen and extend their understanding of mathematical ideas (Burns 1995:13, 2007:38; Jacobs \& Ambrose 2009:265). Writing helps learners to make sense of mathematical problems: learners learn how to represent and communicate their thinking through numbers, words and pictures. In a study conducted by Amaral (2010), it was found that writing in mathematics supports the thinking process. The use of different strategies and representations when writing may be because of the various mathematical abilities of the learners who understand mathematical concepts at varying levels. Some learners may write and solve problems at more sophisticated levels than others based on 
their previous knowledge and levels of conceptual understanding (Orton 2004:25). This is expressed through their use of mathematical symbols as found in a study conducted by Mutodi and Mosimege (2016:203). The participants displayed difficulty with understanding the complexity and abstract nature of symbols before their conceptual understanding of the mathematical idea had been mastered. In comparison to this study, learners engaged with the writing of others to compare and learn from the strategies of their peers, thereby developing more advanced or invented problem-solving strategies as Askew (2013) suggests.

In the pre-test and post-test of a study based on Grade 2 intervention conducted by Takane (in process) (Venkat \& Askew 2016:264), increasing sophistication of learners' strategies was evident as in this study. However, the focus of Takane's study appeared to place more emphasis on sensemaking rather than the sophistication of learners' strategies. Findings from the study by Tshesane and Venkat (2014) indicate that the use of specific models as tools can lead towards sophistication of strategies. This finding which used the number line model correlates with this study in that writing tasks were used as a model or tool.

Burns (1995) describes different types of writing tasks and their purpose in developing conceptual understanding. The writing tasks presented in her work were conducted with learners from different grades throughout the primary school years into early high school. Because this study focused on the Foundation Phase, Burns' writing tasks were suitable as her research included learners from these grades. The Curriculum and Assessment Policy Statement Mathematics for Foundation Phase stipulates that learners communicate their own thinking orally and in writing through drawings and symbols (South Africa DBE 2011a:9). The implementation of writing tasks would enable this to occur in the mathematics classroom. Although not directly from Burns' work, shared writing (Wilcox \& Monroe 2011) was added to this study because it linked to the current curriculum guidelines in use in South Africa. Shared writing is an element of the Balanced Language Approach in which learners and the teacher write together (South Africa DBE 2011b:12).

Five writing tasks were implemented. In 'writing to solve mathematical problems', Burns (1995:69) suggests learners solve, explain and justify their thinking by using a variety of strategies to verify and interpret results. Learners use writing in numbers, pictures and words to explain their thinking behind their solution strategies. In 'writing to record (keeping a journal or $\log )^{\prime}$, learners keep ongoing records about what they are doing and learning in their mathematics class, which can be used to record their thinking when they notice something, make an observation or report a discovery (Burns 1995:51). They provide learners with regular opportunities to reflect on mathematics lessons or concepts, analyse their own learning and generate written dialogue between teacher and learner. 'Writing to explain' is considered a form of notetaking where learners define a mathematical concept or term in their own words or summarise what they have learned
(Freed 1994:23). This writing task focuses on learners' abilities to clarify and explain particular mathematical concepts. 'Writing about thinking and learning processes' allows learners to think beyond the actual mathematics lesson. Learners write about their favourite or least favourite activities, qualities of a good problem-solving partner, directions for an activity or game or a letter to visitors describing mathematics activities in the classroom (Burns 2007:40). In 'shared writing', the teacher and learners formulate a mathematical story or poem reflecting their understanding of a particular concept. Teachers use this writing experience in the mathematics classroom to review and internalise mathematical concepts and ideas as well as develop mathematical communication (Wilcox \& Monroe 2011:526). This writing task encourages learners to put their knowledge and understanding of mathematics across in a creative, collaborative way.

Learners were introduced to the use of writing tasks in mathematics, particularly in the area of problem solving. Mathematical problems and, in particular, word problems should form part of problem solving. Heddens and Speer (2006:82) define problem solving as the (interdisciplinary) process an individual uses to respond to and overcome obstacles or barriers when a solution or method of solution to a problem is not immediately obvious'. It involves a process of thinking and reasoning that helps conceptual development rather than procedural development (O'Donnell 2006:351). Heddens and Speer (2006:84) argue the opportunity to apply conceptual knowledge through problem solving is as important as understanding the concepts themselves because it provides more meaning and purpose to the knowledge and skills the learner has acquired. This process allows learners to deepen their conceptual understanding and engage in the process of sense-making: they apply and develop their mathematical knowledge (Schoenfeld 2013). As learners do so, there would most likely be development in their use of problem-solving strategies.

Vygotsky's theories of the zone of proximal development and appropriation underpinned this study. This theoretical framework suited the use of writing tasks in the mathematics classroom while learners solved mathematical problems. The zone of proximal development (Vygotsky 1978) is defined as:

The distance between the actual developmental level as determined by independent problem solving and the level of potential development as determined through problem solving under adult guidance or in collaboration with more capable peers. (p. 86)

In this study, writing activities created the opportunity for a ZPD to be established. Initially, learners engaged in problemsolving activities where their use of strategies and written explanations was limited. Different types of writing tasks were used to guide and support mathematical problemsolving strategies and explanations within the ZPD in order for learners to decrease the distance between their potential development and actual development of their independent strategies. The more knowledgeable other (MKO), be it the 
peer, parent or teacher, scaffolds understanding through individually tailored pacing of the problem-solving process (Bruner \& Haste 1987:8). In a study conducted by Sonne and Graven (2014), it was found that mathematical communication and the role of the MKO can play a critical role in learners' development of problem-solving strategies. Learners engage in problem-solving situations collaboratively in the ZPD with opportunities to explain and discuss mathematical concepts encountered in the problems. Through such situations, scaffolding occurs which leads, in turn, to the learner's construction of independent knowledge and problem-solving abilities. In the ZPD in this study, Burns's (1995) methodology of using writing in mathematics was introduced and implemented as a tool to scaffold learners' use of problem-solving strategies and support them when solving mathematical problems.

Vygotsky's theory of appropriation, as explained by Duarte (2011), is applicable in this study where there is a reflection on the objective reality in thought. As learners engaged in problem solving and personal writing, they were given opportunities to appropriate the concrete problem by reflecting on concepts in their thinking. This view is asserted by Askew's (2013) explanation that, through experiences, learners are able to engage with abstract concepts irrespective of them having reached a certain stage of development.

\section{Aims and objectives of the study}

This study was guided by the following research question:

How do various types of writing tasks support Grade 3 learners in solving mathematical problems?

This article will focus on the extent to which Grade 3 learners are able to engage in writing tasks when solving mathematical problems. It reports on the support that writing tasks give to the development of problem-solving strategies by focusing on the nature of their representations.

\section{Research methods and design Study design}

This qualitative case study was a systematic, in-depth investigation of a particular instance in its context in order to generate knowledge (Rule \& John 2011:4). A pre-test and post-test were conducted at the beginning and end of the data collection period where Grade 3 learners solved five mathematical problems to determine whether there had been improvement in the learners' conceptual understanding and problem-solving strategies. A sample of eight learners was interviewed after the pre-test and post-test to gauge the extent to which learners engaged with writing tasks as well as the support writing tasks had given to their development of problem-solving strategies. Writing tasks were introduced systematically as an intervention to all the learners in the class during the data collection period. In-depth observations of the sample of learners' writing, problem-solving strategies and conceptual development were conducted.
Generic mathematics problems were given to all participating learners during the pre-test, intervention and post-test. The problems related to the basic operations (addition, subtraction, multiplication and division) using whole numbers with varying number ranges to accommodate the different mathematical ability groups in the class. Although the number of test items was limited, learners had the opportunity to solve 13 problems during the intervention. These problems were included in the data collected for this study. Ability group discussions with all learners were conducted after learners solved problems during the intervention. Learners shared their strategies with their peers and were guided to think critically about their own strategies as well as the strategies of others.

The study was conducted in an English medium Foundation Phase school in a suburban area in Cape Town. This school was conveniently selected because the researcher was a Grade 3 teacher at the school. Learners predominantly spoke and understood English. One of the five Grade 3 classes was conveniently selected to keep data collection manageable for the researcher as the teacher of the selected class. The population constituted all the learners of the participating class where writing tasks (Burns 1995; Wilcox \& Monroe 2011) were modelled by the researcher and implemented by the learners during the eight-week intervention period. Data were collected from a purposively selected sample of eight learners. They displayed varying abilities when solving and explaining mathematical problems and represented the three mathematical ability groups present in the Grade 3 class.

\section{Data collection and analysis}

Data were captured by audio-recordings of interviews and ability group discussions, learners' written work during the pre-test, intervention and post-test, and field notes. The sample was interviewed following the pre-test and post-test to explore how writing was used as they solved mathematical problems. Interviews were semi-structured with a flexible list of questions and key themes to allow for probing, follow-up questions and in-depth investigation. After learners solved mathematical problems during the intervention, the different mathematical ability groups in the class discussed their solutions and strategies. Field notes were used to record what learners were doing while solving mathematical problems. Dialogue and conversation were scripted during ability group discussions and collaborative writing between pairs of learners. For the purpose of this article, data collected from learners' written work were analysed to explore the support writing tasks gave to the development of problemsolving strategies through the nature of learners' representations.

The analysis process involved developing initial insights, coding, interpretations and drawing implications (Dana \& Yendel-Hoppey 2009:120). Once data were transcribed and prepared, data were read and reread to extract and describe initial insights and reflect on their overall meaning. The next step involved coding using ATLAS.ti, a computer-assisted 
qualitative data analysis programme, where labels were used to assign different themes or foci within the data (Rule \& John 2011:77). After investigating possible frameworks for the data analysis in this study, the sample learners' problemsolving strategies were analysed and compared using the Learning Framework in Number (LFIN) by Wright, Martland and Stafford (2006). LFIN encapsulates likely stages and levels of number learning that learners progress through as they develop their mathematical knowledge. The LFIN incorporates the following areas of number learning: the Stages of Early Arithmetical Learning (SEAL), number words and numerals, the Structuring Number Strand, conceptual place value knowledge and early multiplication and division. Although LFIN is often used to analyse early number learning, it was appropriately used in this study to focus on and analyse the level of the learners' strategies when they solved mathematical word problems. In a sense, the words of the problems were unpacked to analyse the strategies related to the numbers in the problems. Venkat (2012) employed the stages and levels of LFIN in a similar style in a research project that analysed the development and interventions of mathematics teaching and learning. Boxes 1 and 2 show the stages of SEAL and levels of early multiplication and division.

The coded data were interpreted to communicate findings and conclusions were drawn to explore the extent to which learners engage with the writing tasks and the support writing tasks give to the development of learners' problemsolving strategies.

\section{Ethical considerations}

For the purpose of this study, permission was sought from, and granted by, the Western Cape Education Department, Cape Peninsula University of Technology, the principal of the school and the parents of all the learners in the participating Grade 3 class. An informed consent form was read and signed by the parents of the learner population granting participation in the study. Pseudonyms were used for the school and all participants to maintain confidentiality.

\section{Results and discussion}

During the intervention, learners engaged with the five writing tasks. The following examples show how learners used the tasks and developed the mathematical understanding through writing. When introduced to 'writing to record (keeping a journal or log)' (Burns 1995:51), learners were presented with examples of ways to start sentences that would help to guide their thinking. Figure 1 shows how Kayla used the writing prompts to describe what had happened during the day's mathematics lesson. Learners were given a few opportunities during the intervention to use 'writing to explain' (Freed 1994:23). Bevan's writing (Figure 2) clarifies his understanding of the empty number line after a mathematics lesson. Figures 3 and 4 show two different examples of learners writing as they engaged with 'writing about thinking and learning processes' (Burns 2007:40). Gemma describes her favourite mathematics
BOX 1: Model for Stages of Early Arithmetic Learning.

\begin{tabular}{|c|c|}
\hline Stage 0: Emergent counting & $\begin{array}{l}\text { Cannot count visible items. The child either } \\
\text { does not know the number words or cannot } \\
\text { coordinate the number words with items. }\end{array}$ \\
\hline Stage 1: Perceptual counting & $\begin{array}{l}\text { Can count perceived items but not those in } \\
\text { screened (that is concealed) collections. This } \\
\text { may involve seeing, hearing or feeling items. }\end{array}$ \\
\hline Stage 2: Figurative counting & $\begin{array}{l}\text { Can count the items in a screened collection } \\
\text { but counting typically includes what adults } \\
\text { might regard as redundant activity. For } \\
\text { example, when presented with two screened } \\
\text { collections, told how many in each collection, } \\
\text { and asked how many counters in all, the child } \\
\text { will count from 'one' instead of counting-on. }\end{array}$ \\
\hline $\begin{array}{l}\text { Stage } 3 \text { : Initial number } \\
\text { sequence }\end{array}$ & $\begin{array}{l}\text { Child uses counting-on instead of counting } \\
\text { from 'one' to solve addition or missing addend } \\
\text { tasks (e.g. } 6+x=9 \text { ). The child may use a count- } \\
\text { down-from strategy to solve removed items, } \\
\text { tasks (e.g. } 17-3 \text { as } 16,15,14-\text { answer } 14 \text { ) but } \\
\text { not count-down-to strategies to solve missing } \\
\text { subtrahend tasks (e.g. } 17-14 \text { as } 16,15,14- \\
\text { answer } 3 \text { ). }\end{array}$ \\
\hline $\begin{array}{l}\text { Stage 4: Intermediate number } \\
\text { sequence }\end{array}$ & $\begin{array}{l}\text { The child counts-down-to to solve missing } \\
\text { subtrahend tasks (e.g., } 17-14 \text { as } 16,15,14- \\
\text { answer } 3 \text { ). The child can choose the more } \\
\text { efficient of count-down-from and count- } \\
\text { down-to strategies. }\end{array}$ \\
\hline $\begin{array}{l}\text { Stage 5: Facile number } \\
\text { sequence }\end{array}$ & $\begin{array}{l}\text { The child uses a range of what are referred to } \\
\text { as non-count-by-ones strategies. These } \\
\text { strategies involve procedures other than } \\
\text { counting-by-ones but may also involve some } \\
\text { counting-by-ones. Thus, in additive and } \\
\text { subtractive situations, the child uses strategies } \\
\text { such as compensation, using a known result, } \\
\text { adding to } 10 \text {, commutativity, subtraction as } \\
\text { the inverse of addition, awareness of the ' } 10 \text { ' } \\
\text { in teen number. }\end{array}$ \\
\hline
\end{tabular}

Source: Wright et al. 2006

BOX 2: Model for early multiplication and division levels.

\begin{tabular}{|ll|}
\hline Level 1: Initial grouping & $\begin{array}{l}\text { Uses perceptual counting (that is, by ones) to } \\
\text { establish the numerosity of a collection of } \\
\text { equal groups, to share items into groups of a } \\
\text { given size (quotitive sharing) and to share } \\
\text { items into a given number of groups (partitive } \\
\text { sharing). }\end{array}$ \\
$\begin{array}{l}\text { Level 2: Perceptual counting in } \\
\text { multiples }\end{array}$ & $\begin{array}{l}\text { Uses a multiplicative counting strategy to } \\
\text { count visible items arranged in equal groups. }\end{array}$ \\
$\begin{array}{l}\text { Level 3: Figurative composite } \\
\text { grouping }\end{array}$ & $\begin{array}{l}\text { Uses a multiplicative counting strategy to } \\
\text { count items arranged in equal groups in cases } \\
\text { where the individual items are not visible. }\end{array}$ \\
$\begin{array}{l}\text { Level 4: Repeated abstract } \\
\text { composite grouping }\end{array}$ & $\begin{array}{l}\text { Counts composite units in repeated addition } \\
\text { or subtraction, that is, uses the composite unit } \\
\text { a specified number of times. }\end{array}$ \\
$\begin{array}{l}\text { Level 5: Multiplication and } \\
\text { division as operations }\end{array}$ & $\begin{array}{l}\text { Can regard both the number in each group } \\
\text { and the number of groups as a composite } \\
\text { unit. Can immediately recall or quickly derive } \\
\text { many of the basic facts for multiplication and } \\
\text { division. }\end{array}$ \\
\hline
\end{tabular}

Source: Wright et al. 2006

activity in Figure 3 while Bevan defines the qualities of a problem solver in Figure 4.

The pre-test and post-test used in this study helped to gauge the levels of problem-solving strategies learners used before and after implementing different types of writing tasks. The stages and levels of the different aspects of LFIN (Wright et al. 2006) provided clarity and differentiation between the strategies learners used when solving problems. The findings of the pretest showed that most learners had difficulty solving mathematical word problems and communicating their thinking through writing. Learners sometimes used strategies inappropriate to the problem types. Many learners in the selected Grade 3 class were restricted in their use of mathematical problem-solving strategies in the pre-test. Their 


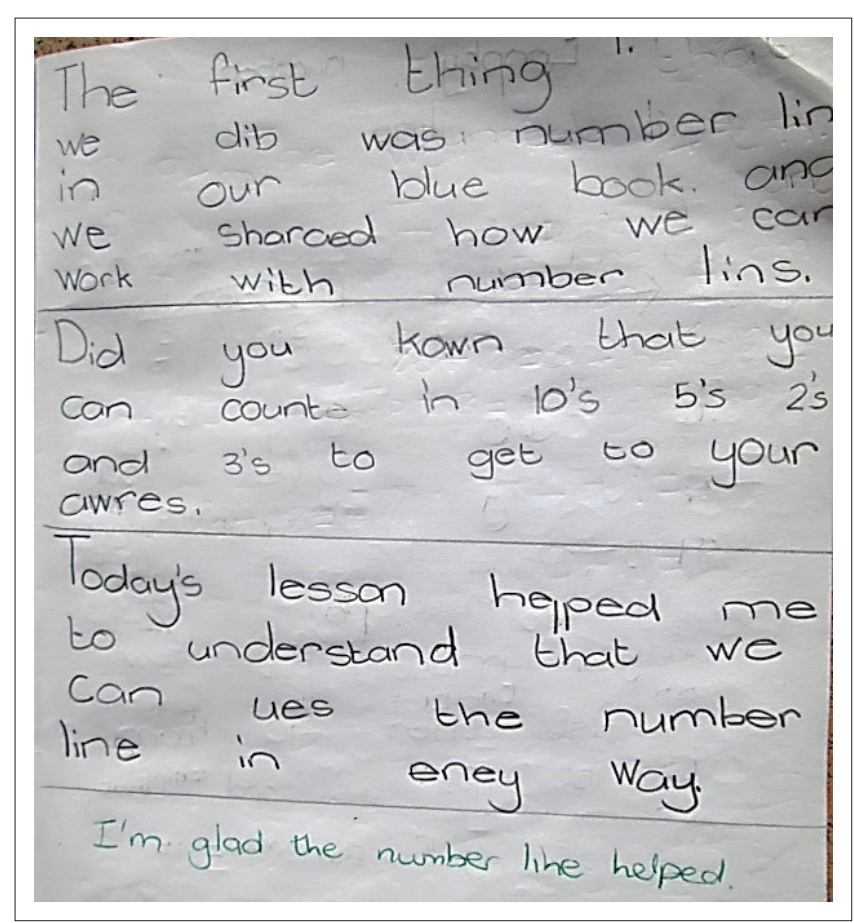

FIGURE 1: Kayla (Journal).

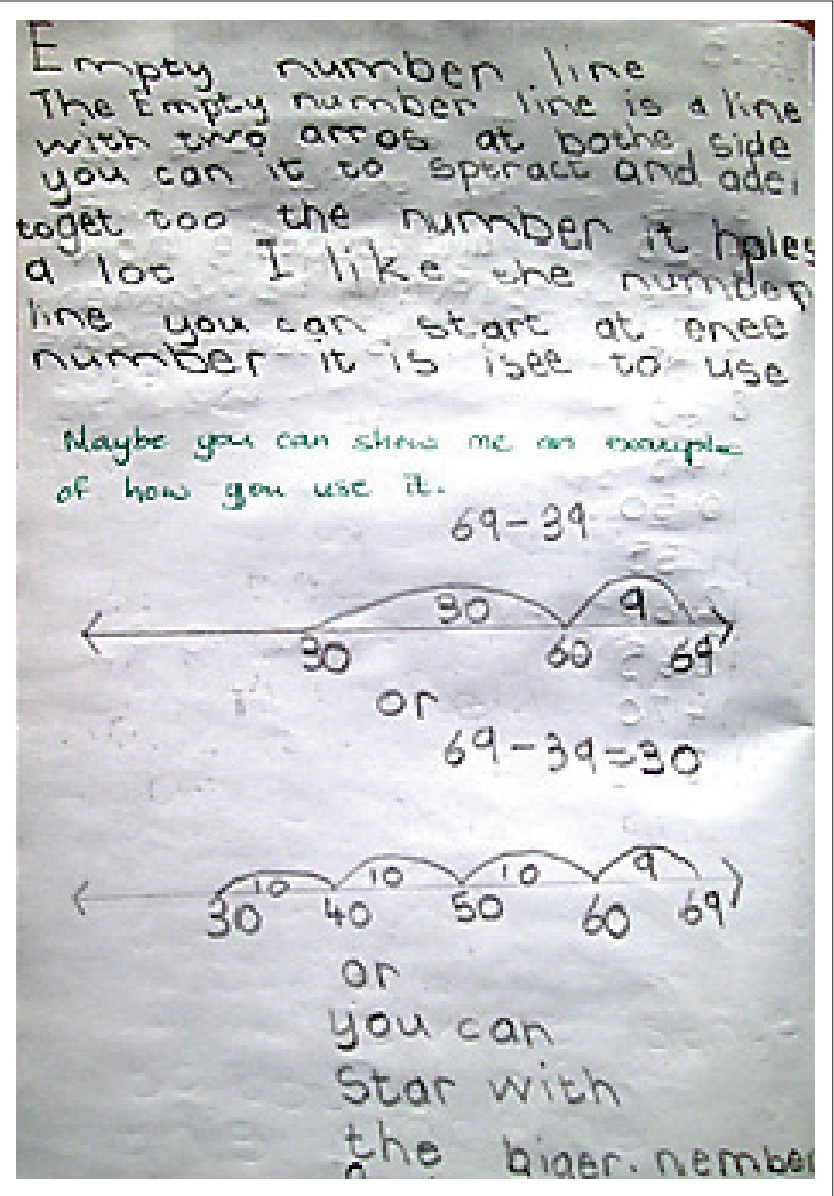

FIGURE 2: Bevan (Explanation).

strategies often reflected lower stages and levels of different aspects of the LFIN. Tallies were frequently used as a strategy in the pre-test (Figure 5) and the earlier part of the writing

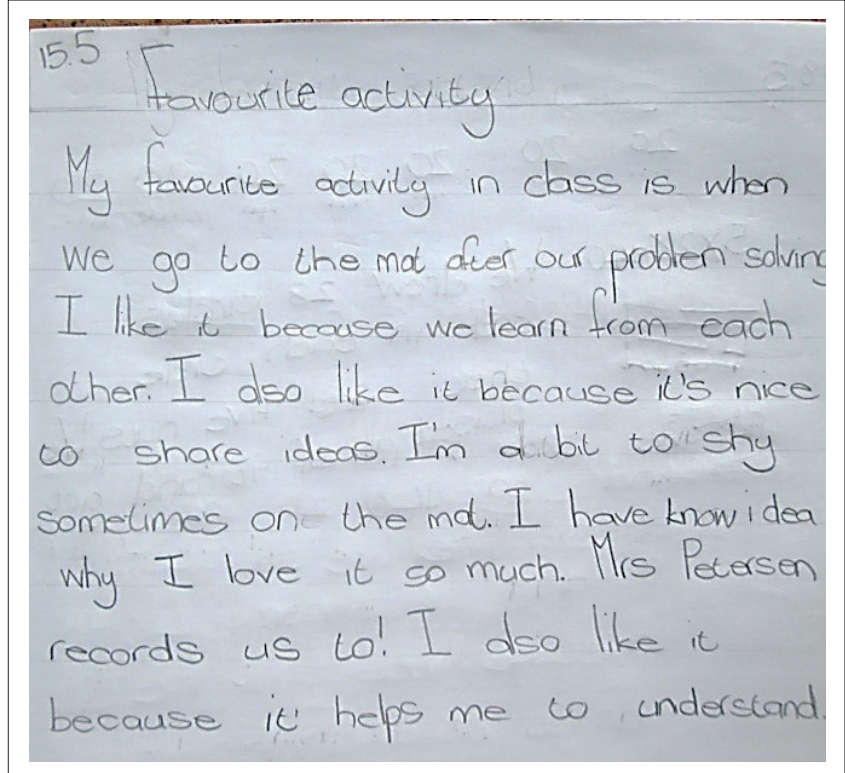

FIGURE 3: Gemma (Thinking and learning processes).

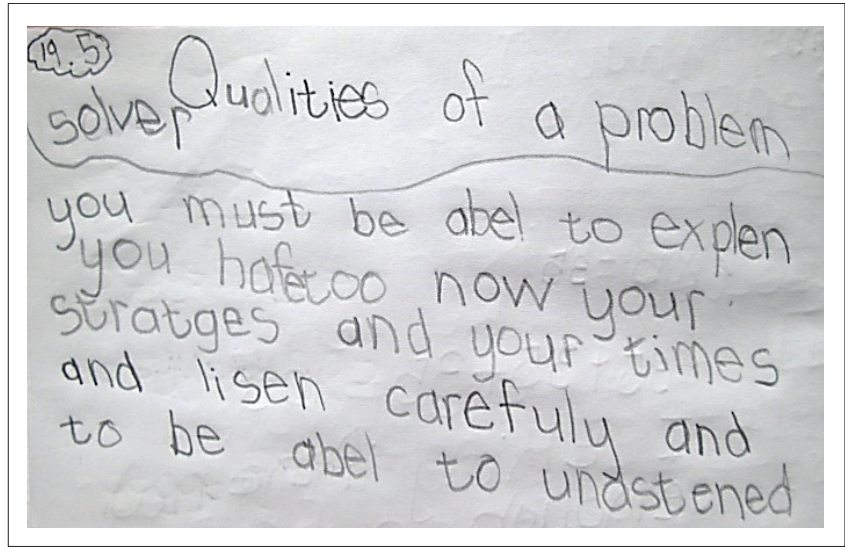

FIGURE 4: Bevan (Thinking and learning processes).

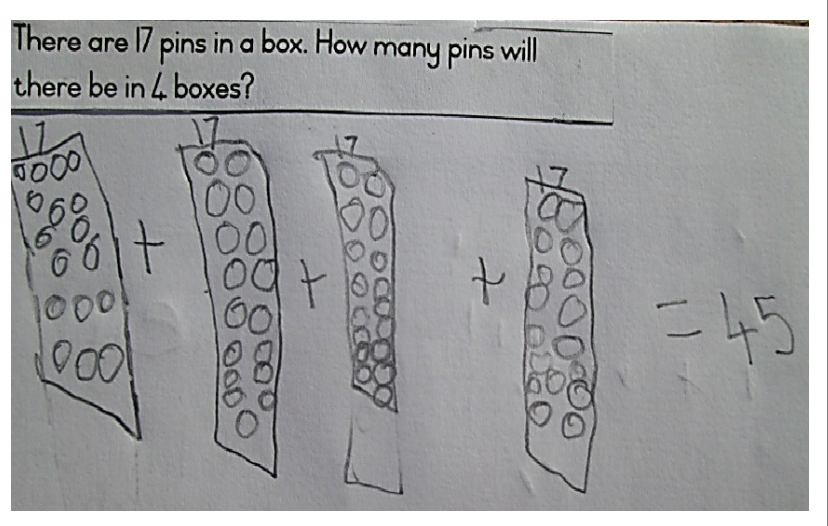

FIGURE 5: Kayla (Pre-test).

intervention. At this point, learners' written explanations were fairly limited. Learners who wrote detailed explanations when solving the problems of the post-test were able to provide detailed verbal explanations of their strategies and solution processes during the post-test interviews. It appeared that their use of writing helped them to make sense of their strategies and justify their thinking when solving problems (Burns 1995:13). 
The results showed an improvement in the level of problemsolving strategies used as learners made less use of tallies, for example. This improvement was particularly evident among the below-average learners as shown in Figures 6 and 7 . Initially, Jarred used perceptual counting as a strategy to solve this problem:

The tricycle factory has 65 wheels available. How many tricycles can they assemble with the wheels?

While discussing the written feedback the following day, the learner was probed to explain what he thought this meant while the researcher circled his tallies of the wheels to make a group of three wheels. This technique was at level 1 (initial grouping)

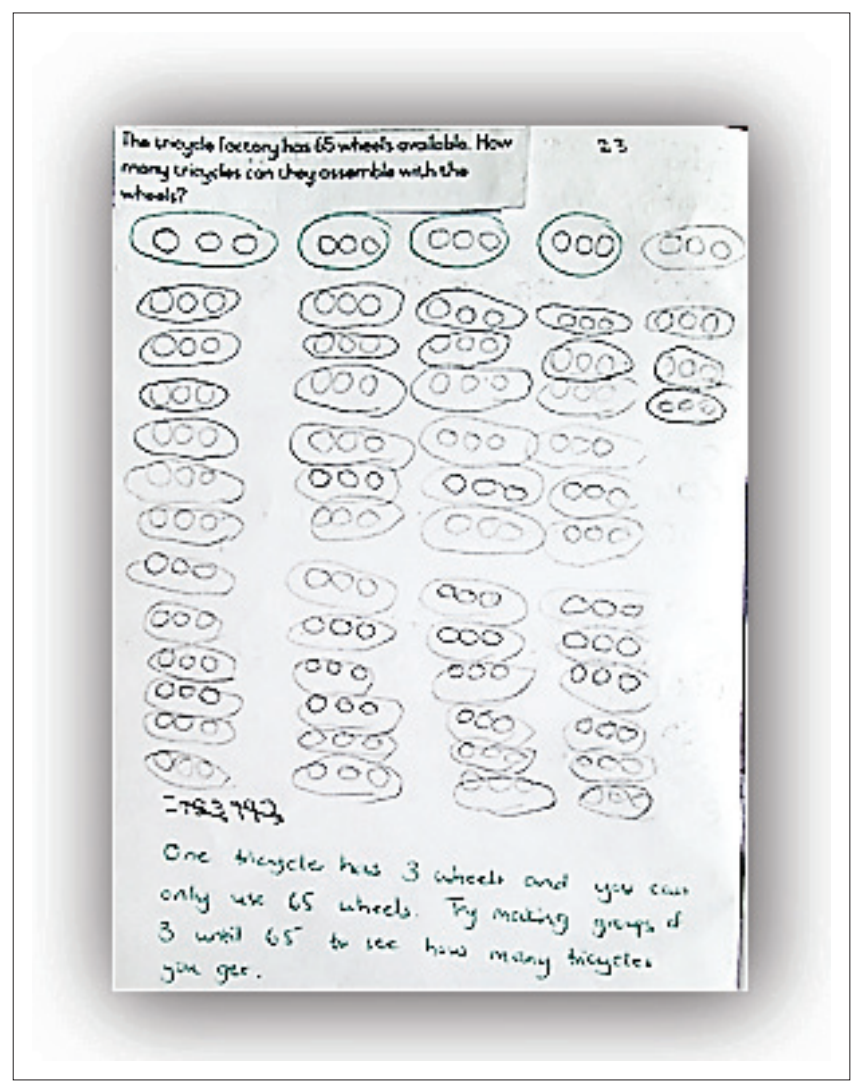

FIGURE 6: Jarred (Intervention-Problem 5).

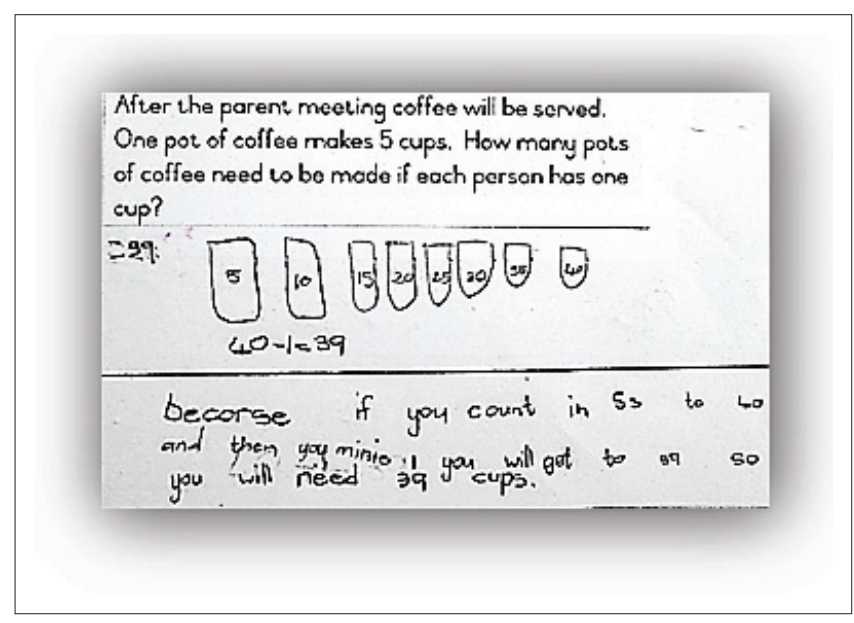

FIGURE 7: Jarred (Post-test). of early multiplication and division. The learner gave an appropriate verbal explanation that each group represented one tricycle with three wheels. He continued to solve the problem on his own. Later, as the researcher analysed what he had done, it became clear that he had still misinterpreted the problem. He continued circling all his tallies into groups of three without counting his tally marks. This caused him to go beyond the 65 wheels mentioned in the problem. An explanation was written by the teacher to prompt further thinking about the number of tallies needed to represent the wheels in the problem. This difficulty in understanding the complexity of symbols before mastering the conceptual understanding was expressed in the study by Mutodi and Mosimege (2016).

The problem in the post-test (Figure 7) was the second part of a problem where 39 parents attended a parent meeting. It read as follows:

After the parent meeting coffee will be served. One pot of coffee makes 5 cups. How many pots of coffee need to be made if each person has one cup?

Jarred represented his strategy using a drawing, numbers and words that made sense. His strategy reflected figurative composite grouping, level 3 of early multiplication and division. He used repeated addition in such a way where each group is represented as an abstract composite unit (Wright et al. 2006). He wrote an explanation that detailed how he solved the problem (Jacobs \& Ambrose 2009:265). He understood the mathematical concept required in the problem, which was counting in fives. He did not rely on counting by ones and used a strategy that required higher order thinking. However, he did not continue to provide the solution which was eight pots of coffee. At this stage, learners had already encountered the concepts of counting by threes and fives in prior mathematics lessons. The strategies being used in these two problems by the same learner shows how he progressed from initially using tallies, where he was counting by ones, to counting in composite groups of five without tallies later during the post-test. The use of explanations in the writing tasks may have contributed to this improvement in his use of problemsolving strategies.

Figures 8 and 9 compare strategies and explanations used by an above-average learner. The pre-test problem read:

There are 17 pins in a box. How many pins will there be in 6 boxes?

In this pre-test problem, Gemma used division instead of multiplication. In the post-test, she was the only learner to use conceptual place value in her problem-solving strategy to solve the following problem:

Mark and Martha packed out 81 chairs. Mark packed out 48 chairs. How many did Martha pack out? 


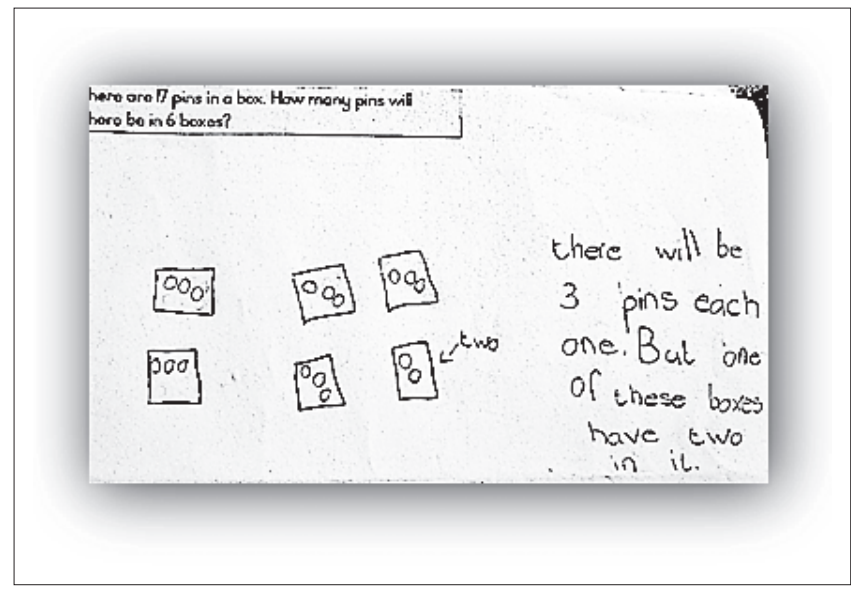

FIGURE 8: Gemma (Pre-test).

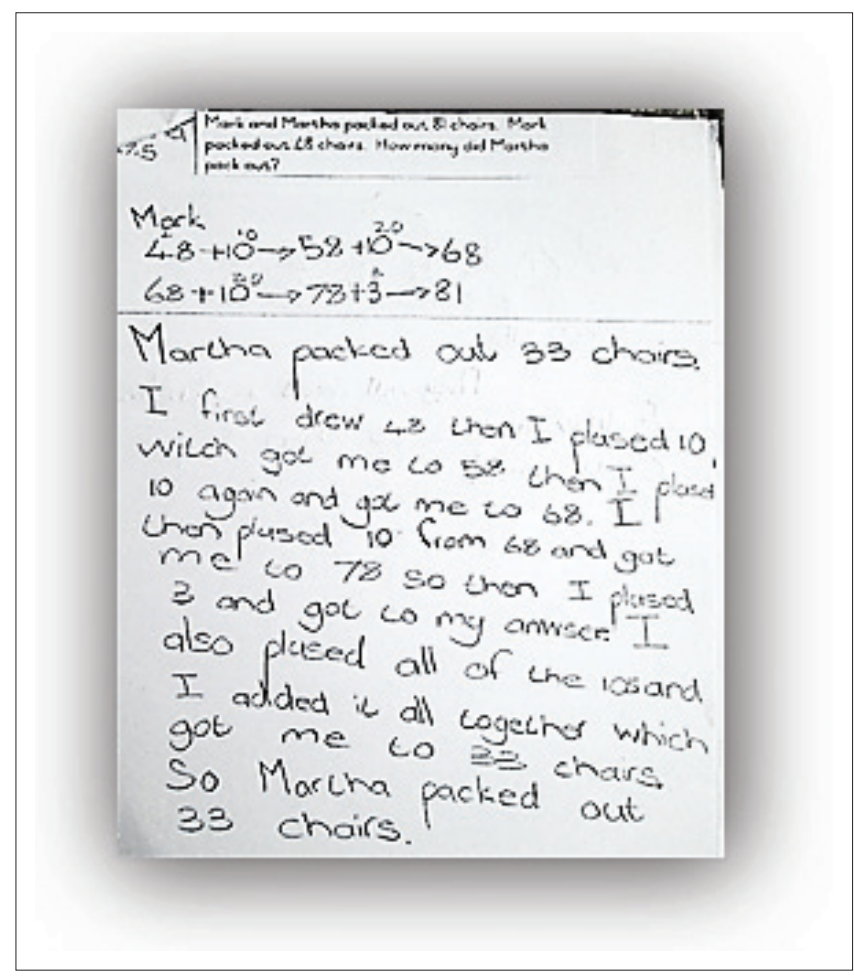

FIGURE 9: Gemma (Post-test).

In her strategy, she incremented by tens off the decuple to work out the difference between 48 and 81 . She provided a detailed explanation of her strategy through her writing, which justified her thinking demonstrating deeper conceptual understanding. This improvement in her use of a more advanced strategy that reflected a higher level of LFIN could possibly be attributed to the writing intervention she had received.

Throughout the data collection period, learners were encouraged to connect the problem they were solving to a mathematical concept or idea. Initially, some learners, especially from the average and below-average ability groups, had difficulty finding the mathematical concept or idea within the problem. As the writing intervention progressed, learners increasingly engaged in writing tasks in a way that encouraged them to think through their strategies and solutions in order to write an explanation of their thinking (Burns 1995:69). In Figure 10, Gemma wrote an explanation that helped the researcher to understand how she solved the problem. By writing a response, Gemma was prompted to review her strategy, find her error and write a further explanation. Development of their conceptual understanding was particularly evident in the post-test where learners individually wrote more detailed explanations incorporating mathematical ideas.

Figure 11 is an example of the development of learners' problem-solving strategies and their use of writing during the intervention. Gemma's initial strategy shows her use of tallies in solving the following problem:

32 birds land on the bird table. There are now 91 birds there. How many birds were already on the table?

Learners were given an opportunity to share their problemsolving strategies and explanations in an ability group discussion. After engaging with other learners' strategies, Gemma was able to solve the problem by combining her conceptual knowledge of place value and subtraction to find the solution. She had arrived at the same solution using a more sophisticated strategy after the discussion. At this stage of the intervention period, her written explanations of her strategies were still limited.

The majority of problem-solving strategies used by learners in the post-test reflected higher stages and levels of LFIN, suggesting that they were able to connect the mathematical content and context of the problem to their existing knowledge (Orton 2004:25). In some instances, learners combined mathematical concepts in their strategies portraying deeper conceptual understanding (Figure 12). For this problem, 57 parents attended the meeting. It read:

After the parent meeting coffee will be served. One pot of coffee makes 7 cups. How many pots of coffee need to be made if each person has one cup?

Initially, this average-ability learner used the doubling strategy to a point and incorporated this into a repeated addition sum. Bevan successfully combined two strategies from his prior knowledge, which demonstrates a deeper conceptual understanding. At this stage, learners had not encountered the concept of counting by sevens. He was able to use his knowledge of doubling numbers and adding seven each time rather than reverting to tallies and counting by ones.

These results reflect that the learners' thinking was appropriated concretely through their strategies and explanations as they solved problems and engaged in writing tasks. Learners employed the five writing tasks in order to make sense of mathematical ideas and express their thinking: their use of writing revealed their individual development of thought. 


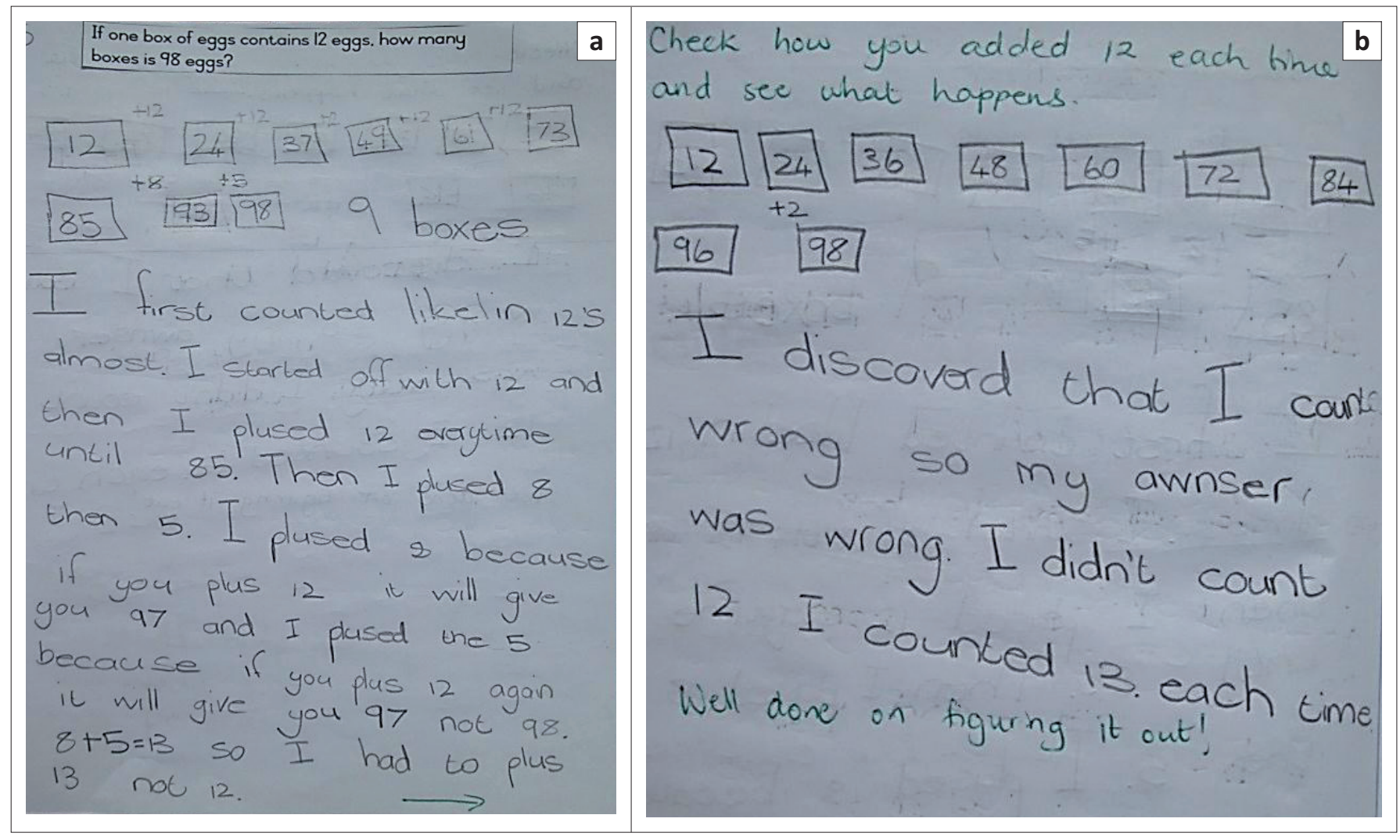

FIGURE 10: Gemma (Intervention-Problem 8).

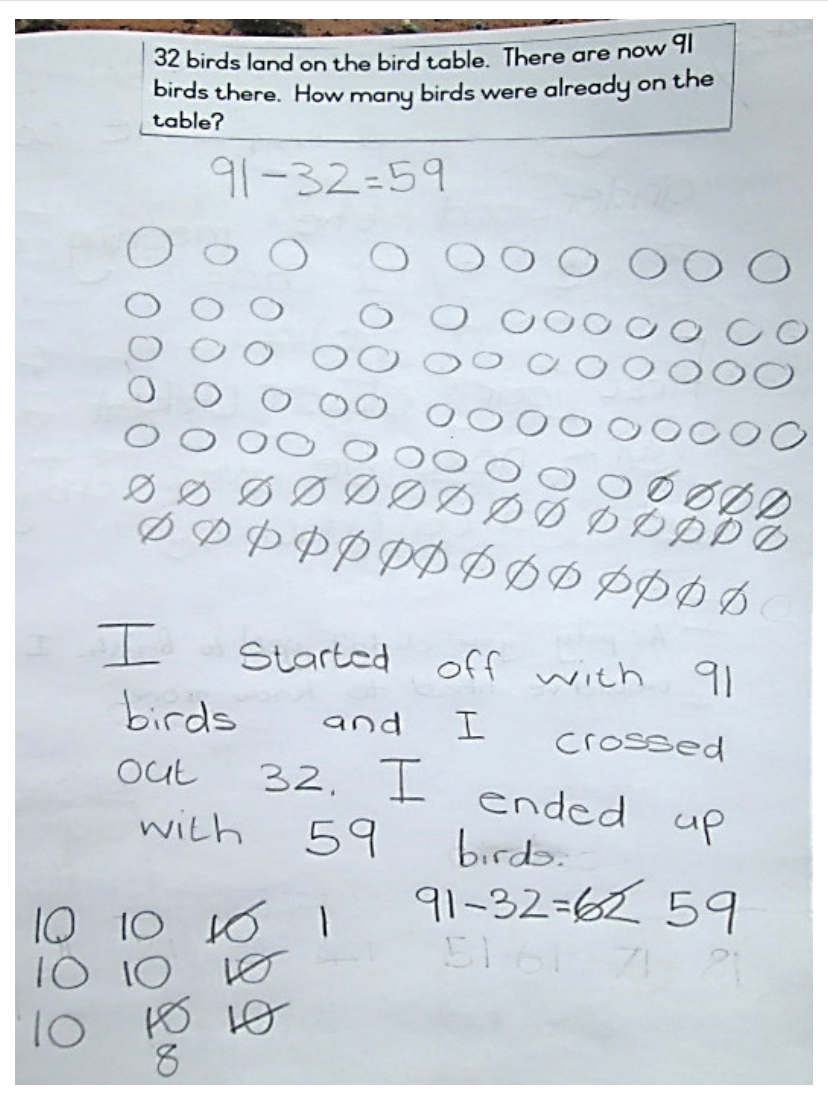

FIGURE 11: Gemma (Intervention-Problem 1).

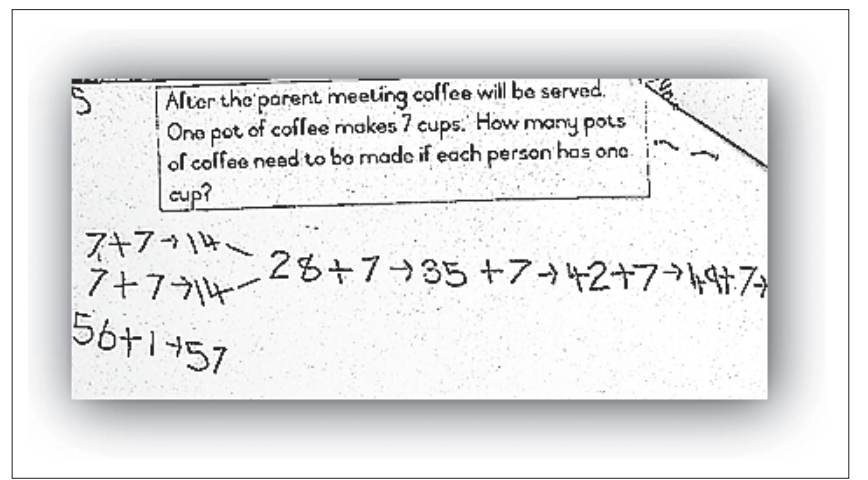

FIGURE 12: Bevan (Post-test).

\section{Conclusion}

Burns' (1995) writing methodology was used as a means to support learners' mathematical problem-solving strategies in the South African Foundation Phase context. Writing tasks were used as an intervention with a class of Grade 3 learners during the data collection period. Data were collected from a sample of eight learners. The intervention demonstrated the development of their problem-solving strategies as they applied their conceptual knowledge. Learners were using more advanced strategies by the end of the data collection period. The examples given show that there was a distinct difference in the nature of learners' representations when results of the pre-test and the post-test were compared. 
Five writing tasks were modelled to learners and implemented during the intervention. One of the writing tasks, 'writing to solve mathematical problems' was used during the pre-test and post-test. The learners' use of this writing task revealed the extent to which learners were able to engage with at least one of the writing tasks. This independent use of writing suggests that the use of writing tasks may increase learners' ability to describe the thinking behind their solution processes when they engage in mathematical problem solving. Selected learners were able to provide written explanations of their solutions in order to justify their strategies.

The aim of this article focuses on the support writing tasks give to Grade 3 learners while solving mathematical problems. It explored the extent to which learners were able to engage with the writing tasks and the support writing tasks give to the development of problem-solving strategies and the nature of learners' representations. Although the scope of this article is limited, the use of writing methodologies such as Burns's (1995) may be useful in the South African context. Venkat and Askew (2016) suggest that materials and pedagogic approaches such as this methodology be adapted to address the issues and needs of the South African mathematics classroom.

The results of this study suggest that writing is beneficial in the mathematics classroom. A more comprehensive study may be required on the use of each writing task to support the development of problem-solving strategies. Learners' talk can be explored during the ability group discussions and collaborative work in relation to their development of problem-solving strategies. Further in-depth research can be conducted in the Foundation Phase as well as higher grades to determine the usefulness of writing in mathematics across the phases and stages of the mathematics curriculum.

\section{Acknowledgements}

This study was in part made possible through a grant by the University Research Fund of the Cape Peninsula University of Technology

\section{Competing interests}

The authors declare that they have no financial or personal relationships which may have inappropriately influenced them in writing this article.

\section{Authors' contributions}

C.V. and S.M. were the project supervisors. B.P., C.V. and S.M. co-designed the project. B.P. implemented the project, collected the data and analysed the data. B.P., C.V. and S.M. co-formulated the results, discussion and conclusion.

\section{References}

Amaral, S.S., 2010, ‘Children's discursive representations of their mathematical thinking: An action research study', master's dissertation, University of Manitoba, Winnipeg, MB.

Askew, M., 2013, 'Mediating learning number bonds through a Vygotskian lens of scientific concepts', South African Journal of Childhood Education 3(2), 1-20. https://doi.org/10.4102/sajce.v3i2.37

Bruner, J. \& Haste, H. (eds.), 1987, Making sense: The child's construction of the world, Routledge, London.

Burns, M., 1995, Writing in math class: A resource for grades 2-8, Math Solutions, Sausalito, CA.

Burns, M., 2007, About teaching mathematics: A K-8 resource, Math Solutions, Sausalito, CA.

Dana, N.F. \& Yendel-Hoppey, D., 2009, The reflective educator's guide to classroom research: Learning to teach and teaching to learn through practitioner inquiry, Corwin Press, Thousand Oaks, CA.

Duarte, N., 2011, 'Vygotsky and the dialectical appropriation of reality by scientific knowledge', paper presented at the International Society for Cultural and Activity Research, Rome, 8 September.

Freed, S., 1994, 'Writing in math classes', The Journal of Adventist Education 56(3), 22-26.

Graven, M., Stott, D., Mofu, Z. \& Ndongeni, S., 2015, 'Identifying stages of numeracy proficiency to enable remediation of foundational knowledge using the learning framework in number', in Proceedings at the 23rd Annual Conference of the Southern African Association for Research in Mathematics, Science and Technology Education in Maputo, Mozambique, 13-16 January, pp. 69-83.

Heddens, J.W. \& Speer, W.R., 2006, Today's mathematics: Concepts, classroom methods and instructional activities, 11th edn., Wiley, Hoboken, NJ.

Jacobs, V.R. \& Ambrose, R.C., 2009, 'Making the most of story problems', Teaching Children Mathematics 15(5), 260-266.

Mutodi, P. \& Mosimege, M., 2016, 'The challenges of constructing mathematical meaning through symbolisation at secondary school level: Some instructional strategies', in Proceedings of the 24th Annual Conference of the Southern African Association for Research in Mathematics, Science and Technology Education, Pretoria, South Africa, 12-15 January, pp. 196-207.

Ndlovu, M. \& Mji, A., 2012, 'Alignment between South African mathematics assessment standards and the TIMSS assessment frameworks', Pythagoras 33(3), 182-190. https://doi.org/10.4102/pythagoras.v33i3.182

O'Donnell, B., 2006, 'On becoming a better problem-solving teacher', Teaching Children Mathematics 12(7), 346-351.

Orton, A., 2004, Learning mathematics: Issues, theory and classroom practice, 3rd edn., Continuum, London.

Rule, P. \& John, V., 2011, Your guide to case study research, Van Schaik, Pretoria.

Schoenfeld, A.H., 2013, 'Reflections on problem solving theory and practice', The Mathematics Enthusiast 10(1), 9-34.

Sonne, A. \& Graven, M., 2014, 'Investigating how problem-solving skills can be developed using a collaborative learning environment', presentation at the $22 \mathrm{nd}$ Annual Conference of the Southern African Association for Research in Mathematics, Science and Technology Education, Maputo, Mozambique, 13-16 January.

South Africa. Department of Basic Education (DBE), 2011a, Curriculum and assessment policy statement: English mathematics, Department of Basic Education, Pretoria.

South Africa. Department of Basic Education (DBE), 2011b, Curriculum and assessment policy statement: English home language, Department of Basic Education, Pretoria.

Tshesane, H. \& Venkat, H., 2014, 'Models and strategies for additive relations in primary mathematics: Findings from a case study', paper presented at the Proceedings of the 22nd Annual Conference of the Southern African Association for Research in Mathematics, Science and Technology Education, Maputo, Mozambique, 13-16 January.

Venkat, H., 2012, 'Wits maths connect - Primary', presentation at the Community of Practice Forum, Johannesburg, 20-21 August.

Venkat, H. \& Askew, M., 2016, 'Materials “borrowing” and adapting: Overviewing "Big Books" interventions in primary mathematics classrooms', paper presented at the Proceedings of the 24th Annual Conference of the Southern African Association for Research in Mathematics, Science and Technology Education, Pretoria, South Africa, 12-15 January.

Vygotsky, L.S., 1978, Mind in society: The development of higher psychological processes, Harvard University Press, London.

Wilcox, B. \& Monroe, E.E., 2011, 'Integrating writing and mathematics', The Reading Teacher 64(7), 521-529. https://doi.org/10.1598/RT.64.7.6

Wright, R.J., Martland, J. \& Stafford, A.K., 2006, Early numeracy: Assessment for teaching and intervention, 2nd edn., Paul Chapman Publishing, London. 